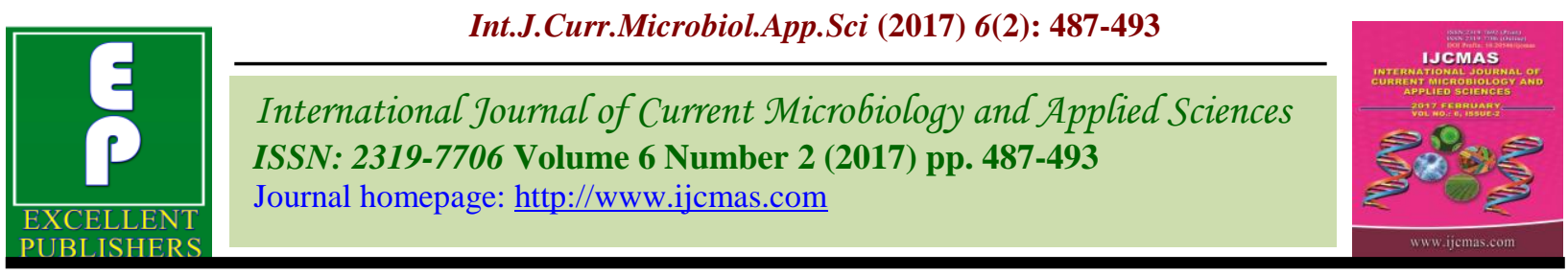

Original Research Article

http://dx.doi.org/10.20546/ijcmas.2017.602.055

\title{
Phytochemical Analysis, Antibacterial and Antioxidant Activity of Tylophora indica
}

\author{
M. Ranemma ${ }^{1}$, E. Nagendram ${ }^{2}$, S. Niranjan ${ }^{1}$, A. Narshimha Reddy ${ }^{1}$ and Ch. Mohan ${ }^{1}$. \\ ${ }^{1}$ Department of Botany, Osmania University, Hyderabad-500007, Telangana, India \\ ${ }^{2}$ Department of Biochemistry, Osmania University, Hyderabad-500007, Telangana, India \\ *Corresponding author
}

\section{A B S T R A C T}

\section{Keywords}

Tylophora indica, Phytochemical analysis, Qualitative analysis,

Antimicrobial, Antioxidant activity.

Article Info

Accepted:

15 January 2017

Available Online:

10 February 2017
The present paper reports the phytochemical analysis, antibacterial and antioxidant activity of a threatened plant Tylophora indica (Burm. F.) Merill is a threatened medicinal plant (climber) which belongs to the family Asclepiadaceae. is a slow growing perennial medicinal woody climber it is commonly used to treat Asthma and there is a growing demand for leaves of $T$. indica in the pharmaceutical trade due to its use as a remedy for diabetes and also as a tonic of the nerves and as a laxative other ailments. Phytochemical studies were taken up and the presence of alkaloids, flavonoids, phenols, saponins, steroids, tannins and terpenoids was confirmed by qualitative analysis and antibacterial activity of extracts of different $T$. indica explants were performed against gram positive and gram negative bacteria by the disk diffusion method. The activities of the compounds were compared with standard strain for antibacterial properties of the imine base and its solvent extract evaluated and presenting in indicate that the compounds are active in exhibiting antibacterial role also carried out. $T$. indica exhibited potent antioxidant activity by inhibiting DPPH free radicals which indicates the roots and leaves extract is very much source of natural antioxidant agent.

\section{Introduction}

Plants have been used for the treatment of various diseases all over the world before the advent of modern clinical drugs and are known to contain substances that can be used for therapeutic purposes or as precursors for the synthesis of useful drugs (Sofowora, 1982). Thus over $50 \%$ of these modern drugs are of natural products origin and as such play an important role in drug development in the pharmaceutical industry (Jeyachandran, 2007). Tylophora indica commonly known as antamool is a perennial twining medicinal herb belonging to family Asclepiadaceae. It is a threatened plant, is distributed in Assam,
West Bengal and Peninsular India. It is used as a traditional folk medicine and as an ingredient in Ayurvedic and Unani medicine. It is used to treat asthma, inflammation, bronchitis, diarrhoea, allergies, rheumatism, dermatitis, syphilis, fever, eye diseases, urinary disorders (Gupta et al., 1979), burning sensation and also used in antitumor treatment (Donaldson et al., 1968). The herb contains certain bioactive compounds like Alkaloids, Flavonoids, Tannins and Saponins, (Rao, 1971; Benjamin, 1973). Phytochemical analysis from leaves and root explants was also reported by (Mohan et al., 2014). There 
is a great demand for Tylophora indica for production of traditional and modern medicine in pharmaceutical industries. Due to the over exploitation from its natural habitat, it has also been listed as a threatened plant.

Antibacterial 1 activities of several plant products have gained importance in recent times. Plant derived secondary metabolites like alkaloids, terpenoids and flavonoids have shown to interfere with many biological activities. They possess antibacterial, antifungal, cyotoxic or antitumour, antifeedant and insecticidal activities (Purohit et al., 1995; Abubakar, 2009). Although T. indica is a versatile medicinal plant, placing in restricted localities in Indian sub continents and parts of Africa, the information on the antifeedant, antimicrobial and antifungal activity of Tylophora species is insufficient. Hence the present study was carried out on phytochemical analysis, antibacterial activity and to estimate the antioxidant potential and free radical scavenging properties of different parts such as root and leaves of Tylophora indica (Burm f.) Merrill methanolic extracts through DPPH in vitro assay.

\section{Materials and Methods}

Material: Tylophora indica plants were collected from Herbal garden, N. G. Ranga Agricultural University at Hyderabad. The collected plant materials were identified by Taxonomist Department of Botany. Tylophora indica is a slender climber with twining woody stem and opposite petiolate leaves, which are entire, shiny, smooth, varying in shape and size according to their age.

Flowers are small, in auxiliary and sessile racemes. The root is long, rigid and cylindrical. The plants were subjected to photochemical analysis (qualitative) and antibacterial activity of the plant extract was also taken up.

\section{Preparation of extracts}

Plant samples were washed with distilled water and air-dried at room temperature for 7 10 days, then oven-dried at $40{ }^{0} \mathrm{C}$ to remove the residual moisture. The dried plant parts were pulverized and stored in air-tight containers at $4{ }^{0} \mathrm{C}$ for future use. $50 \mathrm{~g}$ of powdered samples of bark, flowers and leaves were extracted with methanol by soxhlation method at 60 to $80{ }^{\circ} \mathrm{C}$. The three filtrates were separately concentrated in water bath at $40{ }^{\circ} \mathrm{C}$ and evaporated under reduced pressure.

\section{Qualitative analysis}

Test for identification of alkaloids: The leaf extract was prepared (ground in $100 \mathrm{ml}$ of water). It was dissolved in dilute $\mathrm{HCl}$ solution and clarified by filtration. The filtrate was tested with Drangendroff's and Mayer's reagent. The treated solution was observed for precipitation of white or creamy colour.

Test for identification of flavonoids: Ethyl acetate $(5 \mathrm{ml})$ was added to the leaf extract and the mixture was shaken and allowed to settle. Production of green colour is taken as positive for flavonoids.

Test for identification of phenols: The leaf extract was taken in a test tube $(0.5 \mathrm{gm}$ of roots ground in $100 \mathrm{ml}$ of water) and warmed. To this $2 \mathrm{ml}$ of ferric chloride was added and observed for formation of green or blue colour.

Test for identification of saponins: The root extract was taken in a test tube and shaken vigorously for about $30 \mathrm{sec}$ and allowed to stand in vertical position and observed for 30 min. If honey comb froth above the surface of the liquid persists after $30 \mathrm{~min}$, it indicates the presence of saponins.

Test for identification of steroids: The extract was mixed with $2 \mathrm{ml}$ of acetic 
anhydride. To this 1 or 2 drop of concentrated sulphuric acid was added slowly along the sides of the test tubes. An array of color change shows the presence of phytosterols.

Test for identification of tannins: The leaf extract was prepared and the solution was clarified by filtration. $10 \%$ ferric chloride solution was added to the clear filtrate, and it was observed for a change in colour to blue.

Test for identification of terpenoids: $5 \mathrm{ml}$ of the extract was mixed with $2 \mathrm{ml}$ of chloroform and concentrated sulphuric acid to form a layer. A reddish brown coloration of the interface showed the presence of terpenoids.

\section{Antibacterial activity}

The disc diffusion method was used to evaluate the antibacterial activity of the synthesized compounds against four bacterial strains viz; E. coli, $P$. aeruginosa, $K$. pneumoniae and $S$. aureus. Each organism was cultured in nutrient broth at $37{ }^{\circ} \mathrm{C}$ for 24 h. Then $1 \%$ broth culture containing approximately 106 colony forming units $(\mathrm{CFU} / \mathrm{mL})$ of test strain was added to nutrient agar medium at $45{ }^{\circ} \mathrm{C}$ and poured into sterile petri plates. The medium was allowed to solidify. $5 \mu \mathrm{L}$ of the test compound (40 $\mathrm{mg} / \mathrm{mL}$ in DMSO) was poured on $4 \mathrm{~mm}$ sterile paper discs and placed on nutrient agar plates. In each plate standard antibacterial drug (ampicillin) and metal complexes were added. The plates were incubated at $37^{\circ} \mathrm{C}$ for $24 \mathrm{~h}$ and the antibacterial activity was determined by measuring the diameter of zones showing complete inhibition ( $\mathrm{mm})$.

\section{Radical scavenging activity}

The percentage of free radical scavenging activity is shown in figure 2 . This assay is based on decrease in absorbance value of $\mathrm{DPPH}$ at $517 \mathrm{~nm}$ on addition of complex. The experiment involves diluting the working solution of the plant (root and leaves) methanol extracts and the ascorbic acid standard (700, 600, 500, 400, 300 and 200 $\mu \mathrm{g} / \mu \mathrm{L}-1)$ in methanol. DPPH concentration was kept constant ( $2 \mathrm{~mL}, 0.004 \%)$. To this varying concentration of plant extracts and standard were added. The mixture was shaken vigorously and kept in dark for $30 \mathrm{~min}$ at room temperature. Then the absorbance was measured at $517 \mathrm{~nm}$ in a spectrophotometer. The whole experiment was carried out using spectroscopic grade methanol solvent at 298 $\mathrm{K}$. The radical scavenging activity has been measured by using the following Eq. 1;

Suppression ratio $\left.(\%)=\left[\left(\mathrm{A}_{0}-\mathrm{A}_{\mathrm{i}}\right) / \mathrm{A}_{0}\right)\right] \mathrm{X}$ $100 \%$ (1)

Where $A_{i}=$ the absorbance in the presence of the plant sample extract, $A_{0}=$ the absorbance in the absence of the plant sample extract.

\section{Results and Discussion}

The present study comprises phytochemical (qualitative) studies in $T$. indica plant extract (methanol and aqueous) was carried out for alkaloids, flavonoids, phenols, saponins, steroids, tannins, and terpenoids. All of the phytochemicals like alkaloids flavonoids, phenols, saponins, steroids and terpenoids were present in Tylophora indica except Tannins (Table 1 and Fig. 1). Whereas, our study reports the absence of Tannins (Mohan et al., 2014; Kumar et al., 2011), indicated that Tannins were present in $T$. indica in the aqueous extract. Several medicinal properties have been attributed to Tannins by (Okwu, 2004) but surprisingly, Tannins were not found in the present study. Alkaloids are however reported in the present study which agrees with the findings of (Meera et al., 2009) who has attributed analgesic, antispasmodic and bactericidal effects. The present study also reports Saponins, similar to the report of (Mohan et al., 2014). Alkaloids 
and Saponins are known to be effective for the treatment of syphilis and other venereal diseases, had earlier reported that Saponins have antibiotic properties and so help the body to fight infections and microbial invasion. Also, it is used as a mild detergent and in intracellular histochemistry staining to allow antibody access to intracellular proteins. These proteins were also reported in hyperchlolesterolaemia, hyperglycaemia, antioxidant, anticancer, anti-inflammatory and weight loss and have anti-fungal properties (Singh et al., 2010) reported the presence of tylophorine alkaloids in $T$. asthamatica. Investigation of $T$. indica for the presence of tylophorine is therefore needed in exclusive studies The presence of flavonoids are reported in $T$. indica presently which is in agreement with (Mohan et al., 2014) who also reported the diuretic property of extracts of $T$. indica is very valuable information. The present study which agrees with the findings of Manjula et al., (2013) and Rama et al., (2014) reported about medicinal plants.

The antibacterial screening of the $T$. indica leaf extracts were performed against gram positive ( $S$. aureus) and gram negative bacteria (E. coli, $P$. aeruginosa and $K$. pneumoniae) by the disk diffusion method. The activities of the compounds were compared with standard ampicillin for antibacterial activity. The antibacterial properties of the imine base and its solvent extract evaluated and presenting in figure 1 and table 2 , indicted that the compounds are active in exhibiting antibacterial role like leaf $0.4,0.2,0.5$ in gram negative bacteria and leaf 0.6 in gram positive bacteria. Study confirms the antibacterial activity of leaf extract of $T$. indica the extract found effective bacterial strain, the activity of leaf extract antibacterial activity higher than in gram negative bacteria, where as more when compare to in gram positive bacteria. However reported in the present study which agrees with the findings of were reported in medicinal plants like (Reddy et al., 2009; Vani et al., 2016; Mohan et al., 2016).

The model of scavenging the stable DPPH radical is a widely used technique to screen antioxidant properties by spectrophotometer in a very short time period. When the reaction between antioxidant molecule and DPPH radical occurs, it results in decrease in absorbance at $517 \mathrm{~nm}$. This is because the radical is scavenged by antioxidants through donation of hydrogen to form the reduced form (DPPH-H), and this property is also visually noticeable as the color changes from purple to yellow. The more rapidly the absorbance decreases, the more potent is the antioxidant compound. In the present study the antioxidant activity of root and leaves extract was evaluated by scavenging stable DPPH radical (Fig. 2).

Table.1 Qualitative analysis of $T$. indica

\begin{tabular}{|c|c|c|c|}
\hline \multirow[t]{2}{*}{ S.No } & \multirow{2}{*}{$\begin{array}{l}\text { Test for } \\
\text { Phytochemicals }\end{array}$} & \multicolumn{2}{|c|}{ Test results } \\
\hline & & Leaf & Root \\
\hline 1 & Alkaloids & $+v e$ & $+v e$ \\
\hline 2 & Flavonoids & $+v e$ & $+v e$ \\
\hline 3 & Phenols & $+v e$ & $+v e$ \\
\hline 4 & Steroids & $+v e$ & $+v e$ \\
\hline 5 & Tannins & $-v e$ & $-v e$ \\
\hline 6 & Terpenoids & $+v e$ & $+v e$ \\
\hline 7 & Saponins & $+v e$ & $+v e$ \\
\hline
\end{tabular}


Table.2 Minimum inhibition zone $(\mathrm{mm})$ complexes $(\mu \mathrm{g} / \mathrm{ml})$ leaf extract of Tylophora indica.

\begin{tabular}{|c|c|c|c|}
\hline \multicolumn{2}{|c|}{ Bacterial inhibition zone (mm) Gram (+) } & Bacterial inhibition zone (mm) Gram (-) \\
\hline E. coli & P. aeruginosa & K. pneumoniae & S. aureus \\
\hline 0.4 & 0.2 & 0.5 & 0.6 \\
\hline
\end{tabular}

Fig.1 Antimicrobial activity of leaf extract of Tylophora indica (A) E. coli, (B) P. aeruginosa (C) K. pneumoniae (Gram Negative) and (D) S. aureus (Gram Positive) ampicillin as positive control

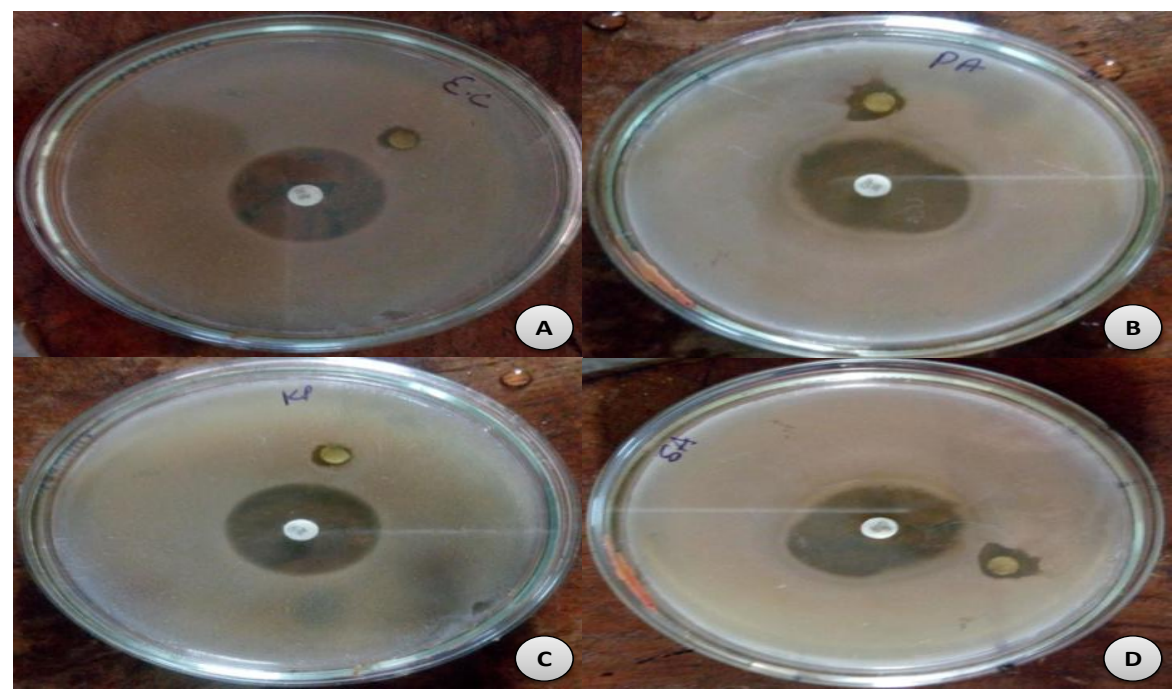

Fig.2 Radical-scavenging activity of the root and leaf extract of $T$. indica on DPPH radicals $(\%)$

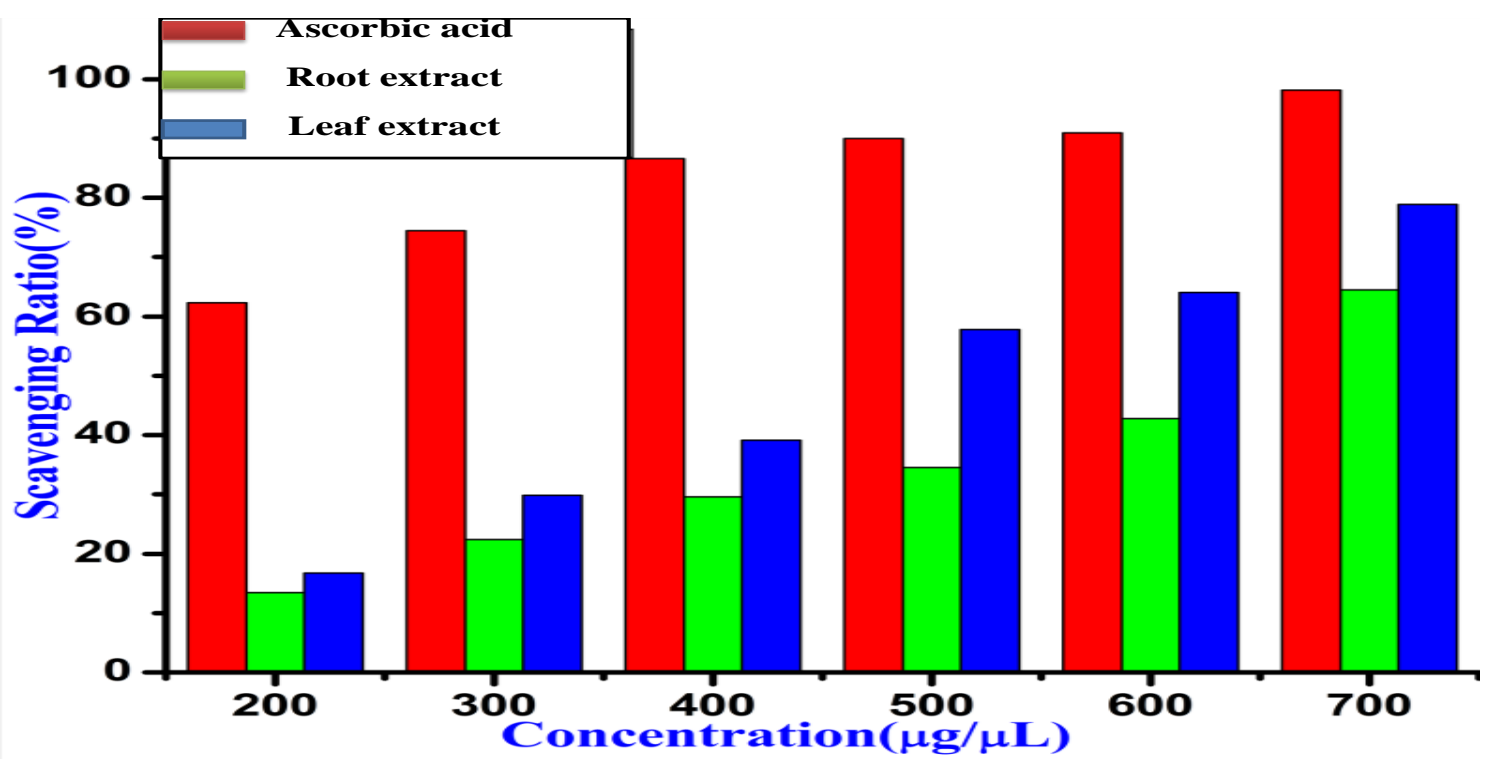


The DPPH radical scavenging activities were found to be $63.03 \%$ for ascorbic acid, 12.85 $\%$ for root and 17. $24 \%$ leaf extract, at concentration of the $200 \mu \mathrm{g} / \mu \mathrm{L}^{-1}$. Ascorbic acid exhibited higher DPPH scavenging activity than the compound at all concentrations. At the concentration of 700 $\mu \mathrm{g} / \mu \mathrm{L}^{-1}$ scavenging activities were found to be $89.85 \%, 80.15 \%$ and $64.12 \%$ for Ascorbic acid, root and leaf extract of respectively. The compounds scavenging activity which is the measure of antioxidant property at the concentration of above compounds at $200 \mu \mathrm{g} / \mu \mathrm{L}^{-1}$ follows the order: Ascorbic acid > root $>$ leaf extract of while at higher concentration the same order is followed by root and leaf extraction exchanged their position the present study results which agree and similar with the findings of (Sharma et al., 2014; Aruna, 2013; Vani et al., 2016).

In conclusion, Tylophora indica is an important medicinal plant with a variety of ethnic medicinal uses. The present study describes the valuable medicinal plant which is used in treating various disorders. The qualitative analysis of $T$. indica shows the presence of bioactive compounds such as alkaloids, flavonoids, phenols, saponins, steroids, tannins and terpenoids. Antibacterial properties of the imine base and its solvent extract evaluated and presenting in indicted that the compounds are active in exhibiting antibacterial role like leaf $0.4,0.2,0.5$ in gram negative bacteria and leaf 0.6 in gram positive bacteria. Study confirms the antibacterial activity of leaf extract of $T$. indica the extract found effective bacterial strain, the activity of leaf extract antibacterial activity higher than in gram negative bacteria, where as more when compare to in gram positive bacteria is a plant with a variety of ethnic medicinal uses. T. indica exhibited potent antioxidant activity by inhibiting DPPH free radicals which indicates the roots and leaves extract is very much of $T$. indica can be used as an accessible source of natural antioxidant agent. This is valuable information for preparation of drugs in pharmaceutical industry and stress the need for more intensive research since they play a great role in healthcare.

\section{References}

Aruna bhatia, Manju anand, Rupali Single and Arpit Sharma. 2013. Antioxidant activity of native and micropropagated Tylophora indica leaves extract: A comparative study, J. Nat. Prod. Plant Res, 3(1): 1-7.

Benjamin, B.D and Mulchandani, N.B. 1973. Studies in biosynthesis of secondary constituents in tissue culture of Tylophora indica. Plant A Med., 23: 394-397.

Donaldson, G.R., Atkinson, M.R and Murray, A.W. 1968. Inhibition of protein synthesis in Ehrlich ascites-tumor cells by the Phenanthrene alkaloids tylophorine, tylocrebrine cryptopleurine. Biochem Biophys Res. Commun., 31: 104-109.

Gupta, S., George, P., Gupta, V., et al., 1979. Tylophora indica in bronchial asthma-a double blind study.Indian J Med Res., 69: 981-989.

Jeyachandran, R and Mahesh, A. 2007. Antimicrobial evaluation of Kigelia africana (Lam). Res. J. Microbiol., 2(8): 645-649.

Krishna Reddy, B., Balaji, M., Uma Reddy, P., Sailaja, G., Vaidyanath, K and Narasimha, G.2009. Antifeedant and antimicrobial activity of Tylophora indica African J. Biochem. Res., Vol.3 (12), pp. 393-397.

Kumar, S., Kaushik, N., Edrada-Ebel, R., Ebel, R., Proksch, P. 2011. Isolation,characterization and bioactivity of endophytic fungi of Tylophora indica. World J. Microbiol. Biotechnol., 27(3): 571-577.

Manjula, P., Mohan, Ch., Sreekanth, D., 
Keerthi, B. and Prathibha Devi, B. 2013 Phytochemical analysis of Clitoria ternatea linn. a valuable medicinal plant. J. Indian Bot. Soc., 92(3\&4): 173-178.

Meera, R., Devi, P., Muthumani, P., Kameshwari, B and Eswarapriya, B. 2009. Evaluation of Diuretic activity from Tylophora indica leaves extracts. $J$. Pharm. Sci. Res., Vol 1(3): 112-116.

Mohan, Ch., Rama devi, B., Manjula, P. and Prathibha Devi, B. 2014. Phytochemical investigations and micropropagation of Tylophora indica (burm. F.) Merill from nodal explants. J. Indian Bot Soc., 93(1\&2): 42-49.

Mohan, Ch., Kistamma, S., Vani, P and Narshimha Reddy, A. 2016. Biological Activities of Different Parts of Saraca asoca an Endangered Valuable Medicinal Plant, Int. J. Curr. Microbiol. Appl. Sci., 5(3): 300-308.

Muhammad Abubakar, E.M. 2009. Efficacy of crude extracts of garlic (Allium sativum L.) against nasocomial Escheria coli, Staphylococcus aureus, Streptococcus pneumoniea and Pseudomonas aeruginosa. J. Med. Plants, 3(4): 179-185.

Okwu, D.E. and Okwu, M.E. 2004. Chemicalcomposition of Spondias mombin Linn. Plant parts. J. Sustain Agric. Environ., 6: 140-147.

Purohit, M.G., Santhaveerappa, B.K., Shrisailappa, B., Swamy, H.K.S. 1995. Anti microbial activity of various extracts of Evolvulus alsinoids, Ind. J. Microbiol., 35(1): 77-78.

Rama Devi, B., Mohan, Ch., Sreekanth, D and Prathibha Devi, B. 2014. Phytochemical and micropropagation studies in Hemidesmus indicus (L.) R. Br. J. Indian Bot. Soc., 93(1\&2): 76-81.

Rao, K.V., Wilson, R.A and Cummings, B. 1971. Alkaloids of Tylophora. 3 New Alkaloids of Tylophora indica (Burm) Merrill and Tylophora dalzelii Hook. J. Pharmaceut. Sci., 60(11): 1725-1726.

Sharma Madan Mohan, Verma Roop Narayan, Singh Abhijeet and Batra Amla. 2014. Antioxidant and free radical scavenging properties of Tylophora indica (burm. F.) Merrill an anti-asthmatic plant, Asian J. Pharm. Clin. Res., Vol 7, Supp 12: 174-176.

Singh, A., Duggal, S. and Sabkar Katekhaye. 2010. Tylophora asthmatica Wight\& Arn. Revie. Nature of Pharmaceutical Technol., 1(1) 1-4.

Sofowora, A. 1982. Medicinal plants and traditional medicine in Africa. 2nd Edn. Ibadan John Willey and Sons ltd; 1982, p. 8-14.

Vani, P., Kistamma, S., Srinivas Reddy, K., Narshimha Reddy, A and Mohan, Ch. 2016. Antibacterial activity, antioxidant activity and micropropagation of Gymnema sylvestre R.Br. a valuable medicinal plant. J. Pharmacognosy and Phytochem., 5(2): 207-210.

\section{How to cite this article:}

Ranemma, M., E. Nagendram, S. Niranjan, A. Narshimha Reddy and Mohan, Ch. 2017. Phytochemical Analysis, Antibacterial and Antioxidant Activity of Tylophora indica. Int.J.Curr.Microbiol.App.Sci. 6(2): 487-493. doi: http://dx.doi.org/10.20546/ijcmas.2017.602.055 